\title{
ПРАВОВЫЕ РЕЖИМЫ, ОСНОВАННЫЕ НА ПРЕИМУЩЕСТВАХ: К ВОПРОСУ О ПОНЯТИИ
}

\begin{abstract}
Аннотация: В статье впервые в юридической литературе предпринимается попытка общетеоретического анализа сущности и содержания правового режима, основанного на преимуществах. Рассматриваются имеющиеся в юридической литературе взгляды на природу, сущность и содержание правовых режимов, устанавливающих для субъектов особые льготы (преимущества, привилегии), характеризуются его признаки. Исследуются цели, особенности нормативно-правового закрепления, принципы, гарантии данных правовых режимов. Обращается внимание на проблему законности существования правового режима, основанного на преимуществах для некоторых категорий субъектов права, и возможности его отступления в отдельных случаях от принципа равенства всех перед законом и судом. В работе использованы различные общенаучные приемы и способы логического познания: анализ и синтез, абстрагирование, моделирование, системно-структурный, функциональный и формально-логический подходы. Специальные методы представлены конкретно-социологическим и статистическим, а частнонаучные - формально-юридическим, сравнительно-правовым и методом толкования норм права. По итогам исследования предлагается авторское определение правового режима, основанного на преимуществах. Он определяется как особый порядок правового регулирования общественных отношений, заключающийся в определенном сочетании правовых средств - дозволений (субъективных прав, законных интересов, льгот, привилегий, иммунитетов, поощрений и т.д.), гарантий и принципов, направленный путем создания благоприятных условий для удовлетворения интересов субъектов права на достижение оптимального социального состояния.
\end{abstract}

Ключевые слова: правовой режим, правовые премущества, дозволения, льготы, иммунитеты, гарантии, пордяок регулирования, социальное состояние, правовое средство, принципы

$\Pi$ онятие «правовой режим» в настоящее время широко используется как в нормативно-правовых актах различного уровня, так и в научной литературе, является одной из важнейших и широко распространенных категорий в общей теории права и государства и в отраслевых науках. В то же время, несмотря на то, что данная категория правомерно востребована различными областями научного знания и юридической практикой, это понятие прочно вошло в юридическую терминологию и общественно-политический лексикон для обозначения различных правовых со- стояний, можно констатировать, что оно остается одним из наиболее сложных и недостаточно изученных в правоведении.

Проблема усугубляется еще и тем, что даже в рамках узкоотраслевых исследований понятие правового режима часто используется как «обиходное», уже известное и не нуждающееся в уточнении. В исследованиях подобного рода правовой режим нередко упоминается только в названии работы. Как результат, растет количество научных трудов, в которых данное понятие употребляется применительно к объектам правового регулирова-

Публикация подготовлена в рамках выполнения государственного задания Министерства образования и науки Российской Федерации по теме: «Юридическая деятельность и ее процессуальное оформление» (заявка 2014/ 78) 
ния (особенно в отраслях права), видам деятельности, субъектам права и т.д. подчас относительно свободно и часто неоправданно, без учета предназначения и истинной сущности рассматриваемой категории в системе правового регулирования.

Все эти негативные тенденции - следствие недостаточного научного освоения всех возникающих вопросов относительно понятия правового режима в общей теории права и государства, отсутствия его целостной непротиворечивой теории (концепции).

Таким образом, в целях преодоления узкоотраслевого понимания правовых режимов (по сути, сведения их к определению объектов права) и неоправданного использования их в контексте нормативно-правовых актов и научных исследований необходима постановка проблемы изучения правовых режимов как фундаментального общетеоретического направления.

Решению данной проблемы в определенной степени способствует и представленное исследование, в котором реализована попытка определить сущность и содержание такого явления, как «правовой режим, основанный на преимуществах».

Сущность (основное предназначение) любого правового режима состоит в установлении на определенном участке правовой действительности особого порядка (климата, напряженности) правового регулирования, заключающегося в создании для субъектов права преимуществ (стимулов, льгот и т.д.) или ограничений (обязываний, запретов и т.д.) в целях реализации прав и законных интересов последних.

В юридической науке распространены два основных подхода к классификации правовых режимов в рассматриваемой плоскости.

Согласно первому подходу, в свое время предложенному С.С. Алексеевым, по соотношению типов (способов) правового регулирования правовые режимы принято делить на общедозволительные, разрешительные и основанные на позитивном обязывании ${ }^{1}$.

Согласно второму подходу, по соотношению стимулов и ограничений отдельные авторы выделяют стимулирующие и ограничивающие правовые режимы с соответствующими подвидами: дозволительные, рекомендательные, обязывающие, запрещающие и т.д. ${ }^{2}$.

\footnotetext{
1 См.: Алексеев С.С. Общие дозволения и общие запреты в советском праве. С. 190-191.

2 См. напр.: Малько А.В., Родионов О.С. Правовые режимы в российском законодательстве // Журнал российского права. 2001. № 9. С. 19-22.
}

Следует отметить, что некоторые различия в названной терминологии при достаточной схожести подходов в определении сущностных свойств правовых режимов, объясняются различным углом зрения на феномен правового режима.

Так, С.С. Алексеев под правовым режимом понимает «порядок регулирования, выраженный в комплексе правовых средств, характеризующих особое сочетание взаимодействующих между собой дозволений, запретов, а также позитивных обязываний и создающих особую направленность регулирования» ${ }^{3}$.

Основной акцент в определении правового режима ученый делает на создание особой направленности регулирования путем сочетания определенных средств и способов такового, поэтому в наименовании видов правового режима указывается на типы правового регулирования, преимущественно лежащие в их основе - общедозволительные (в основе которых дозволения), разрешительные (в основе - запреты), и основанные на позитивном обязывании (обязанности).

В то же время, в своих рассуждениях о правовых режимах С.С. Алексеев признает, что «каждый правовой режим есть все же именно режим; следует принимать во внимание основные смысловые оттенки этого слова, в том числе и то, что правовой режим выражает степень жесткости юридического регулирования, наличие известных ограничений или льгот...»", «... первичные правовые режимы выражают соотношения способов регулирования на определенном участке социальной жизни; вторичные - модификации правовых режимов, вносящие либо особые льготы и преимущества, состоящие в дополнительных правах, либо особые ограничения, которые заключаются в дополнительных запретах или позитивных обязываниях» 5 .

В свою очередь, другие авторы в определении правового режима как «особого порядка регулирования, выражающегося в определенном сочетании юридических средств и создающего желаемое социальное состояние и конкретную степень благоприятности либо неблагоприятности для

\footnotetext{
Алексеев С.С. Общие дозволения и общие запреты в советском праве. С. 185.

4 Алексеев С.С. Теория права. 2-е изд. М., 1995. С. 244.

5 Алексеев С.С. Общие дозволения и общие запреты в советском праве. С. 190.
} 
удовлетворения интересов субъектов права» ${ }^{6}$ ориентируются на информационно-психологический подход, где стимулы, основанные на дозволительном типе правового регулирования, побуждают субъекта права к позитивному поведению и создают для него режим благоприятствования, а ограничения, основанные на разрешительном типе правового регулирования и позитивных обязываниях, ограничивают противоправное поведение субъектов (режим неблагоприятствования) и создают условия для реализации прав и законных интересов других лиц (контрагентов).

В результате, и в первом, и во втором случае отмечается четкая обусловленность правовых режимов типом (способом) правового регулирования, и в то же время, хотя и по-разному акцент делается на особую направленность правового регулирования, основанную на специфическом сочетании правовых средств, в первом случае, и на степень благоприятности (неблагоприятности) для удовлетворения интересов субъектов права (информационно-психологический аспект) - во втором случае.

В то же время, и в том, и другом случае учеными признается тот факт, что правовые режимы создают для субъектов права либо особые преимущества, либо особые ограничения.

В этой связи в рамках настоящего исследования со своей стороны считаем возможным предложить следующее наименование двух больших групп правовых режимов:

- правовые режимы, основанные на преимуществах, в основе которых лежит общедозволительный тип правового регулирования (льготы, привилегии, иммунитеты, поощрения и т.д.);

- правовые режимы, основанные на ограничениях, в основе которых - преимущественно разрешительный тип правового регулирования и позитивные обязывания (запреты, обязанности, приостановления, наказания и т.д.)

Перейдем к изучению правовых режимов, основанных на преимуществах и вначале - о понятии «правовое преимущество».

Преимущество - это а) качество, свойство кого-либо или чего-либо, выгодно отличающие данного человека, данный предмет, данное явление и т. п. от других, демонстрирующие перевес, пре-

6 См., напр.: Матузов Н.И., Малько А.В. Правовые режимы: вопросы теории и практики // Известия вузов. Правоведение. 1996. № 4. С. 17-18. восходство этого человека, предмета, явления над другими; б) чье-либо исключительное право на что-либо (привилегия) ${ }^{7}$.

В юридической литературе родовое понятие «правовое преимущество», равно как и объединенные им видовые понятия «иммунитет», «привилегия», «льгота» и т.д., может рассматриваться в двух аспектах: а) как исключительное статутное право; б) как элемент объективного права (специальная правовая норма) ${ }^{8}$.

Анализ нормативно-правовых актов, закрепляющих правовые преимущества (дипломатические иммунитеты, специальные гарантии профессиональной деятельности представителей органов государственной власти и управления и т.д.) также показывает, что содержащиеся в них нормы права имеют весьма расплывчатые формулировки при определении различного рода иммунитетов, привилегий и льгот, часто данные понятия отождествляются или, наоборот, дифференцируются без достаточных к тому оснований.

Правовые преимущества, как представляется, имеют следующие особенности:

- $\quad$ носят нормативно-правовой характер, то есть подлежат закреплению в действующем законодательстве;

- создают благоприятные (а иногда и сверхблагоприятные) условия для удовлетворения интересов субъектов;

- выражаются в предоставлении субъектам дополнительных гарантий, прав, благ материально- или морально-правового характера (выплата премии, награждение орденами и медалями Российской Федерации), либо в освобождении от какой-либо обязанности (освобождение от уплаты налогов);

- $\quad$ предоставляют определенному лицу дополнительные возможности осуществления прав и реализации интересов;

- направлены на стимулирование социальнополезного поведения субъектов права и тем самым на упорядочение общественных отношений, то есть выступают правовыми средствами.

Теперь проанализируем имеющиеся в юридической науке определения правового режима, основанного на преимуществах, в основе которого

\footnotetext{
http://dic.academic.ru/dic.nsf/dmitriev/4086/преимущество

8 См., напр.: Красильников А.В. Уголовно-процессуальные привилегии отдельных категорий лиц: Дис. ... канд. юрид. наук. М., 2007.
} 
лежит общедозволительный тип правового регулирования ${ }^{9}$.

С.С. Алексеев определяет подобные режимы (в качестве вторичных правовых режимов) как модификации первичных правовых режимов, вносящие «... особые льготы и преимущества, состоящие в дополнительных правах...» ${ }^{10}$.

Думается, что данная позиция ученого, в общем, (и при этом достаточно точно) определяет сущность рассматриваемых правовых режимов, и вот почему. Во-первых, это своеобразная модификация правового режима в целом. Во-вторых, в рамках данного правового режима субъектам представляются особые льготы и дополнительные права.

В то же время, полагаем, при таком подходе отсутствуют сущностные, определяющие характеристики подобных режимов (что, однако, компенсируется, при дальнейшем рассмотрении С.С. Алексеевым правовых режимов общедозволительного профиля) ${ }^{11}$.

А.В. Малько, характеризуя стимулирующий правовой режим, пишет следующее: он «создает благоприятные условия для удовлетворения конкретной группы интересов, а иногда и сверхблагоприятные (режим наибольшего благоприятствования)... Правовые режимы стимулирования могут подразделяться в зависимости от того, какие стимулы в них преобладают... Выделяют дозволительный, рекомендательный, льготный, поощрительный режим, в которых доминируют соответственно дозволения, рекомендации, льготы, поощрения» ${ }^{12}$.

В данном определении уже называются и другие сущностные особенности рассматриваемых правовых режимов: во-первых, в нем содержится указание на такой признак, как создание благоприятных условий для удовлетворения интересов, и, во-вторых, они достаточно четко классифицируются.

В свою очередь, И.Р. Забугин формулирует следующее определение специального правового режима стимулирования: это «установленный нормами права и обеспечиваемый государством порядок правового регулирования, деятельности,

\footnotetext{
9 Уточним, что такое наименование данного правового режима, как «правовой режим, основанный на преимуществах», является авторским предложением, аналогичные наименования в юридической литературе просто отсутствуют.

10 Алексеев С.С. Общие дозволения и общие запреты. С. 190.

11 Там же. С. 191.

12 Малько А.В. Стимулы и ограничения в праве. С. 209.
}

объектов (территорий), представленный позитивными стимулирующими средствами и создающий конкретную степень благоприятности для удовлетворения интересов отдельных субъектов права, целью которого является достижение социального согласия» ${ }^{13}$.

Это определение названного правового режима по ряду моментов можно принять. Например, в той части, где автор признает его специальный характер, представленность позитивными стимулирующими средствами, направленность на создание конкретной степени благоприятности для удовлетворения интересов субъектов права и достижение социального согласия.

В то же время предложенный И.Р. Забугиным перечень объектов рассматриваемого правового режима, вызывает ряд вопросов. Так, по его мнению, правовой режим есть «порядок правового регулирования», «порядок деятельности» и «порядок объектов (территорий)». В первом случае возникает вопрос, порядок правового регулирования чего? Во втором случае - что за «порядок объектов» (а тем более территорий) имеется в виду, и если это новое понятие в юридической науке, то какой смысл в него вкладывается? И последнее, что вызывает неприятие, это указание в определении на нацеленность подобного правового режима на достижение социального согласия. Является ли это утверждением, что другие виды правового режима на это не нацелены или, более того, преследуют цели разжигания социальной розни?

Заметим также, что при всей детальности представленного этим автором определения специального правового режима стимулирования, основные его сущностные характеристики так и не были вскрыты.

Тем не менее, анализ названных и других определений правового режима, основанного на общедозволительном типе правового регулирования, и собственная позиция в данном вопросе позволяют выявить его основные признаки, на основе которых можно сформулировать понятие правового режима, основанного на преимуществах (в нашей терминологии).

Остановимся на характеристике признаков правовых режимов, основанных на преимуществах.

Во-первых, данный правовой режим является видом (модификацией) правового режима в целом,

13 Забугин И.Р. Стимулы в специальных правовых режимах // Вектор науки Тольяттинского государственного университета. 2011. № 1 (4). С. 67. 
который отличает используемый им специфический набор правовых средств, предоставляющих субъектам права преимущества в реализации своих прав и законных интересов и побуждающих их тем самым к законопослушному поведению. Это льготы, привилегии, иммунитеты, поощрения и т.д.

Например, ст. 381 Налогового кодекса РФ устанавливает льготный режим по уплате налогов и сборов в Российской Федерации путем перечисления лиц, освобождающихся от налогообложения. Данный льготный режим является модификацией общего правового режима, сложившегося в сфере налогообложения в Российской Федерации и закрепленного налоговым законодательством Российской Федерации и ее субъектов.

Во-вторых, рассматриваемый правовой режим основан на общедозволительном типе правового регулирования, формирующем в его рамках особый порядок регулирования, представленный специфическим набором правовых способов (дозволений) и средств (субъективные права и законные интересы, льготы, привилегии, иммунитеты, поощрения и т.д.), непосредственно устанавливающих такие преимущества и определяющих их характер.

Дозволение, по верному выражению С.С. Алексеева, составляет ключевой элемент правового регулирования, определяющий правовое средство, призванное обеспечить осуществление реальных прав человека, подлинное самоуправление, творческую и созидательную деятельность людей. Дозволения в праве - это субъективное юридическое право и ему свойственно все то, что присуще субъективным юридическим правам ${ }^{14}$.

В порядке уточнения заметим, что дозволение - это именно возможность (подчеркнуто нами Г.Б.) действовать определенным образом в рамках предоставленного права.

Еще одно определение дозволения предлагает М.К. Юков. По его мнению, дозволение - это установленный нормами права вариант поведения, в соответствии с которым лицу предоставляется право на положительные действия ${ }^{15}$.

В этом случае содержится указание на такой признак дозволения, как закрепление правовыми нормами. И, действительно, дозволение как способ правового регулирования в специальном правовом

\footnotetext{
14 См.: Алексеев С.С. Общие дозволения и общие запреты в советском праве. М., 1989. С. 54.

15 См.: Юков М.К. Дозволения и запреты в системе гражданского процессуального права // Советское государство и право. 1982. № 2. С. 118.
}

режиме должно быть выражено в действующем праве, как правило, в управомочивающих правовых нормах.

По этому поводу С.С. Алексеев пишет следующее: «Указанный момент представляется в высшей степени важным потому, что таким путем - и это определяющая особенность именно юридических дозволений - их содержание очерчивается четкими границами, рамками, отделяющими юридическое дозволение от «просто» произвольных действий» ${ }^{16}$.

Одним из последних исследований правовых дозволений на монографическом уровне является работа К.Е. Игнатенковой, непосредственно посвященная дозволению как способу правового регулирования ${ }^{17}$.

В ней дозволение определяется как «выражающийся посредством юридических норм способ правового регулирования, заключающийся в предоставлении субъекту, в очерченных законом рамках, свободы выбора варианта поведения, стимулирующего его правовую активность, творческие и созидательные качества, способствующего наиболее полному удовлетворению интересов личности, общества и государства» ${ }^{18}$, и с таким подходом в целом можно согласиться.

Представленные определения правовых дозволений позволяют выявить следующие их особенности:

а) правовые дозволения устанавливаются нормами права;

б) предоставляют возможность субъектам права (как частным, так и публичным) действовать по своему усмотрению, следуя при этом нормативным предписаниям.

Надо сказать, что дозволения являются ведущим способом регулирования в гражданском праве. Так, в соответствии с ч. 2 ст. 421 ГК РФ стороны могут заключить договор, как предусмотренный, так и не предусмотренный законом или иными правовыми актами.

Дозволения, как способ правового регулирования, распространены и в административном праве. Например, в соответствии со ст. 2.9 КоАП РФ при малозначительности совершенного администра-

\footnotetext{
16 См.: Алексеев С.С. Право. Азбука. Теория. Философия. Опыт комплексного исследования. М., 1998.

17 См.: Игнатенкова К.Е. Дозволение как способ правового регулирования: Автореф. дис. ... канд. юрид. наук. Саратов, 2006.

18 Там же. С. 9.
} 
тивного правонарушения судья, орган, должностное лицо, уполномоченные решить дело об административном правонарушении, могут освободить лицо, совершившее административное правонарушение, от административной ответственности и ограничиться устным замечанием;

в) цель дозволений состоит в обеспечении осуществления прав граждан, удовлетворении их законных интересов, а также стимулировании социально-полезного поведения.

Основными разновидностями дозволений являются субъективные права, формулируемые по принципу «дозволено то, что разрешено законом», свободы - «дозволено и не подлежит вмешательству со стороны все, что вписывается в установленные законом рамки») и законные интересы - «дозволено все, что не запрещено законом» ${ }^{19}$.

В рамках характеристики общедозволительных начал правового режима, основанного на преимуществах, есть необходимость более подробно остановиться на характеристике правовых средств, непосредственно устанавливающих эти преимущества и определяющих их характер, а, следовательно, и видовую принадлежность данного типа правового режима.

Правовой режим, основанный на преимуществах, может быть представлен такими правовыми средствами, как льготы, привилегии, иммунитеты, поощрения и т.д., объединенными общим родовым понятием «правовое преимущество» ${ }^{20}$.

В-третьих, рассматриваемый правовой режим базируется на системе основополагающих принципов, характерных как для всех видов правовых режимов, так и специализированных принципов, свойственных правовым режимам, основанным на преимуществах, в частности.

К общим принципам правового режима относятся принцип определяющего приоритета в правовом режиме преимуществ или ограничений, принцип законности, принцип юридического равенства, принцип сочетания убеждения и принуждения, принцип социальной справедливости, единство прав и обязанностей, принцип ответственности за вину.

К специализированным принципам можно отнести: принцип единства правовых преимуществ, предполагающий наличие единой нормативной

19 См. подробнее: Игнатенкова К.Е. Дозволение как способ правового регулирования. С. 10.

20 См. подробнее: Беляева Г.С. Правовой режим в общетеоретическом измерении: монография. М., 2013. С. 99-118. базы признания заслуг лица; обоснованности правовых преимуществ; комплексного характера правовых преимуществ; публичного характера применения правовых преимуществ; индивидуализации правовых преимуществ и другие.

В своей системе принципы правовых режимов, основанных на преимуществах, выступают основополагающими положениями (началами), средствами закрепления и регулирования целенаправленного воздействия правовых преимуществ на сознание и психику человека.

В-четвертых, гарантиями правовых режимов, основанных на преимуществах, являются нормативно закрепленные правовые условия, средства (в т.ч. и механизмы), призванные обеспечить реализацию прав и законных интересов субъектов права.

Проиллюстрируем это положение на конкретном примере.

В Федеральном законе от 27.07.2004 № 79-Ф3 «0 государственной гражданской службе Российской Федерации» ${ }^{21}$, в Главе 11 закреплены государственные гарантии на гражданской службе, а именно: 1) равные условия оплаты труда, а также сопоставимые показатели оценки эффективности результатов профессиональной служебной деятельности при замещении соответствующих должностей гражданской службы; 2) право гражданского служащего на своевременное и в полном объеме получение денежного содержания; 3) условия прохождения гражданской службы, обеспечивающие исполнение должностных обязанностей в соответствии с должностным регламентом; 4) отдых, обеспечиваемый установлением нормальной продолжительности служебного времени, предоставлением выходных дней и нерабочих праздничных дней, а также ежегодных оплачиваемых основного и дополнительных отпусков; 5) медицинское страхование гражданского служащего и членов его семьи и другие.

В продолжение темы научный интерес представляет постановление Конституционного Суда РФ от 27 декабря 1999 г. № 19-П²2. Сравнивая правовое положение заведующего кафедрой в государственных высших учебных заведениях и государственных служащих, Конституционный Суд РФ специально отметил, что гарантии и льготы, предусмотренные для последних, призваны компенсировать ущерб,

\footnotetext{
$21 \quad$ СЗ РФ. 2004. № 31. Ст. 3215.

22 См.: СЗ РФ. 2000. № 3. Ст. 354.
} 
наносимый принципу равенства введением отдельных ограничений их прав и свобод.

В Определении Конституционного Суда РФ от 8 июня 2004 г. № 195-0 ${ }^{23}$ отмечается, что специфика государственной службы предопределяет особый правовой статус государственных служащих. Исходя из особенностей этого статуса, обусловленных характером выполняемой государственными служащими деятельности, предъявляемыми к ним квалификационными требованиями, вводимыми ограничениями, связанными с государственной службой, законодатель вправе в рамках специального правового регулирования устанавливать для государственных служащих определенные социальные гарантии в зависимости от вида, продолжительности и условий прохождения государственной службы.

Таким образом, в Федеральном законе «0 государственной гражданской службе Российской Федерации» гарантиями правового режима, основанного на преимуществах, выступают субъективные права и свободы и меры, направленные на охрану, защиту и компенсацию.

В-пятых, нормативно-правовое закрепление правового режима, основанного на преимуществах, также имеет ряд особенностей.

Пределы дозволенного поведения определяются в законодательстве в виде установленных в текстах нормативных актов исключений из общего правила (ограничений в виде конкретных запретов и обязанностей). То есть внешняя (нормативная) объективизация данного типа правового регулирования выражается не в самом дозволении, а в его противоположностях: ограничениях.

Примером правового режима общедозволительного профиля служит правовой режим собственности на землю в гражданском праве (Глава 17 ГК РФ). Так, в ч. 1 ст. 260 ГК РФ закреплено дозволение: «Лица, имеющие в собственности земельный участок, вправе продавать его, дарить, отдавать в залог или сдавать в аренду и распоряжаться им иным образом (статья 209) постольку,

23 См.: Определение Конституционного Суда РФ от 8 июня 2004 г. № 195-О «Об отказе в принятии к рассмотрению запроса Самарского областного суда о проверке конституционности пунктов 2 и 3 статьи 2 Закона Самарской области «Об исчислении стажа государственной службы государственного служащего Самарской области» и пункта 4 приложения к Указу Президента Российской Федерации «О периодах работы (службы), включаемых в стаж государственной службы федеральных государственных служащих, дающий право на установление ежемесячной надбавки к должностному окладу за выслугу лет» // Вестник КС РФ. 2004. № 6. поскольку соответствующие земли на основании закона не исключены из оборота или не ограничены в обороте». А ограничения описывает ч. 2 данной статьи: «На основании закона и в установленном им порядке определяются земли сельскохозяйственного и иного целевого назначения, использование которых для других целей не допускается или ограничивается. Пользование земельным участком, отнесенным к таким землям, может осуществляться в пределах, определяемых его целевым назначением».

В-шестых, цель правового режима, основанного на преимуществах, не является специфическим признаком данного вида правового режима, поскольку, по сути, совпадает с целью правового режима в целом: удовлетворение интересов субъектов права, обеспечение нормального функционирования общественных отношений. Поэтом еще раз повторимся, что «достижение социального согласия» ${ }^{24}$ как цель подобного правового режима не может выступать сущностным его признаком.

В-седьмых, из изложенного выше вытекает следующий признак правового режима, основанного на преимуществах: создание благоприятных условий для субъектов права в реализации своих интересов.

Так, ст. 173 Трудового кодекса РФ устанавливает правовой режим, основанный на преимуществах, для работников, совмещающих работу с обучением в образовательных учреждениях высшего профессионального образования, и работников, поступающих в указанные образовательные учреждения. В рамках данного правового режима создаются следующие благоприятные условия для реализации прав и законных интересов указанных субъектов: дополнительные отпуска с сохранением среднего заработка для прохождения промежуточной аттестации на первом и втором курсах соответственно - по 40 календарных дней, на каждом из последующих курсов соответственно - по 50 календарных дней (при освоении основных образовательных программ высшего профессионального образования в сокращенные сроки на втором курсе - 50 календарных дней) и др.

В итоге, правовой режим, основанный на преимуществах, можно определить как особый порядок правового регулирования общественных отношений, основанный на определенном сочетании правовых средств - дозволений (субъективных прав,

24 Забугин И.Р. Стимулы в специальных правовых режиMax. C. 67. 
Административное и муниципальное право $10(82) \cdot 2014$

законных интересов, льгот, привилегий, иммунитетов, поощрений и т.д.), гарантий и принципов, направленный путем создания благоприятных условий для удовлетворения интересов субъектов права на достижение оптимального социального состояния.

\section{Библиография:}

1. Алексеев С.С. Общие дозволения и общие запреты в советском праве. М., 1989.

2. Алексеев С.С. Право. Азбука. Теория. Философия. Опыт комплексного исследования. М., 1998.

3. Алексеев С.С. Теория права. 2-е изд. М., 1995. С. 244.

4. Беляева Г.С. Правовой режим в общетеоретическом измерении: монография. М., 2013.

5. Забугин И.Р. Стимулы в специальных правовых режимах // Вектор науки Тольяттинского государственного университета. 2011. № 1 (4).

6. Игнатенкова К.Е. Дозволение как способ правового регулирования: Автореф. дис. ... канд. юрид. наук. Саратов, 2006.

7. Красильников А.В. Уголовно-процессуальные привилегии отдельных категорий лиц: Дис. ... канд. юрид. наук. М., 2007.

8. Малько А.В. Стимулы и ограничения в праве. М., 2004.

9. Малько А.В., Родионов О.С. Правовые режимы в российском законодательстве // Журнал российского права. 2001. № 9.

10. Матузов Н.И., Малько А.В. Правовые режимы: вопросы теории и практики // Известия вузов. Правоведение. 1996. № 4.

11. Юков М.К. Дозволения и запреты в системе гражданского процессуального права // Советское государство и право. 1982. № 2.

12. Беляева Г.С. К вопросу о понятии правового режима // Административное и муниципальное право. - 2014. - 3. C. 272 - 285. DOI: 10.7256/1999-2807.2014.3.10938.

13. Беляев В.П. Надзорная процессуальная форма: общетеоретический аспект // Право и политика. - 2014. - 3. C. 404 - 409. DOI: 10.7256/1811-9018.2014.3.11198.

14. Рыльская М.А. Особенности реализации специальных административных режимов // Административное и муниципальное право. - 2012. - 3. - С. 44 - 52.

\section{References (transliterated):}

1. Alekseev S.S. Obshchie dozvoleniya i obshchie zaprety v sovetskom prave. M., 1989.

2. Alekseev S.S. Pravo. Azbuka. Teoriya. Filosofiya. Opyt kompleksnogo issledovaniya. M., 1998.

3. Alekseev S.S. Teoriya prava. 2-e izd. M., 1995. S. 244.

4. Belyaeva G.S. Pravovoi rezhim v obshcheteoreticheskom izmerenii: monografiya. M., 2013.

5. Zabugin I.R. Stimuly v spetsial'nykh pravovykh rezhimakh // Vektor nauki Tol'yattinskogo gosudarstvennogo universiteta. 2011. № 1 (4).

6. Ignatenkova K.E. Dozvolenie kak sposob pravovogo regulirovaniya: Avtoref. dis. ... kand. yurid. nauk. Saratov, 2006.

7. Krasil'nikov A.V. Ugolovno-protsessual'nye privilegii otdel'nykh kategorii lits: Dis. ... kand. yurid. nauk. M., 2007.

8. $\quad$ Mal'ko A.V. Stimuly i ogranicheniya v prave. M., 2004.

9. Mal'ko A.V., Rodionov O.S. Pravovye rezhimy v rossiiskom zakonodatel'stve // Zhurnal rossiiskogo prava. 2001 . № 9.

10. Matuzov N.I., Mal'ko A.V. Pravovye rezhimy: voprosy teorii i praktiki // Izvestiya vuzov. Pravovedenie. 1996. № 4.

11. Yukov M.K. Dozvoleniya i zaprety v sisteme grazhdanskogo protsessual'nogo prava // Sovetskoe gosudarstvo i pravo. 1982. № 2.

12. Belyaeva G.S. K voprosu o ponyatii pravovogo rezhima // Administrativnoe i munitsipal'noe pravo. - 2014. - 3. - C. 272 285. DOI: 10.7256/1999-2807.2014.3.10938.

13. Belyaev V.P. Nadzornaya protsessual'naya forma: obshcheteoreticheskii aspekt // Pravo i politika. - 2014. - 3. - C. 404 409. DOI: $10.7256 / 1811-9018.2014 .3 .11198$.

14. Ryl'skaya M.A. Osobennosti realizatsii spetsial'nykh administrativnykh rezhimov // Administrativnoe i munitsipal'noe pravo. - 2012. - 3. - C. $44-52$. 